\title{
Ecotoxicity and genotoxicity of a binary combination of triclosan and carbendazim to Daphnia magna
}

\author{
Ana Rita R. Silva*†, Diogo N. Cardoso†, Andreia Cruz†, Joana Lourenço†, Sónia \\ Mendo†, Amadeu M. V. M. Soares† and Susana Loureiro*† \\ †Department of Biology \& CESAM, University of Aveiro, 3810-193, Portugal \\ *Email: ritas@ua.pt; sloureiro@ua.pt
}

Ana Rita R. Silva (ritas@ua.pt), Department of Biology \& CESAM, University of Aveiro, 3810-193, Portugal, telephone (+351) 234370 350, fax (+351) 234372587

\section{Abstract}

In the environment, chemical substances appear as complex mixtures and consequently organisms are exposed to a variety of chemicals from different sources (e.g. wastewater treatment plants, agriculture runoffs). When studying chemical mixtures, there are two conceptual models usually used to predict toxicity: the Independent Action (IA) and Concentration Addition (CA) models. However, deviations from these reference models can occur as synergism or antagonism, dose ratio or dose level dependency. The aim of the present study was to investigate the effects of triclosan and carbendazim, and their binary mixture to Daphnia magna. With this purpose, immobilisation, feeding inhibition, and reproduction were assessed as main ecotoxicity endpoints. In addition, in vivo genotoxicity of both chemicals was investigated using the comet assay. In the single exposure, carbendazim was more toxic to D. magna than triclosan. When daphnids were exposed to both single compounds, DNA damage was observed. Concerning mixture exposures, different endpoints 
followed different patterns of response, from additivity: IA model (feeding inhibition and reproduction data), to deviations that indicate interaction between chemicals inside the organism: dose level dependency (immobilisation data) and dose ratio dependency (DNA damage). This study showed that additivity does not rule the dose-effect relation in chemical mixtures of carbendazim and triclosan and interactions between both chemicals might induce generally higher toxicity than predicted based on single chemical exposures.

Key words: single/mixture toxicity; DNA damage; reproduction; feeding inhibition; synergism/antagonism

1. Introduction

During the last decades, the use of pesticides continued to increase, being one of the major sources of pollution for aquatic ecosystems. In addition, other frequent sources of pollution occur from Wastewater Treatment Plants (WWTP) effluents, contributing therefore to the presence of complex mixtures in aquatic systems. The risk assessment of these complex mixtures can be underestimated because procedures account for single toxicity of each chemical and usually do not account for their additivity or possible interactions (Loureiro et al., 2010; Pavlaki et al., 2011).

Given the increasing importance of studying mixtures, this study will provide information regarding the toxic effects of two widely used compounds with possible different origins: carbendazim is applied directly in agricultural crops whereas triclosan is used in many consumer products ending up in wastewater treatment effluents. Usually studies on mixture effects are performed using co-occurring compounds from the same origin, and few focus on the interactions of chemicals from different sources. 
Nevertheless, both compounds enter in the aquatic environment (to surface and groundwater) and can be used as model compounds to understand mixture effects (Lishman et al., 2006; WHO, 1993) Triclosan (TCS) is an antimicrobial agent used in several personal care products, including toothpastes, mouthrinses (Council Directive, 1999 edition; Gaffar et al., 1994) and in other frequently used products, such as plastics, shoes, textiles and food packaging materials (Jones et al., 2000). Triclosan has been used in almost every part of the World including in the European Union, where approximately 350 tons of triclosan are produced annually (Singer et al., 2002). Triclosan has been detected in wastewater treatment effluents at concentrations between 0.01 and $2.7 \mu \mathrm{g} / \mathrm{L}$ (Lishman et al., 2006; Reiss et al., 2002), mainly due to the fact that after entering WWTP, it is not completely removed and consequently it is released to the environment (Bester, 2003). In Portugal, triclosan was detected in urban wastewater samples at low concentrations: 124. $1 \mathrm{ng} / \mathrm{L}$ (Neng and Nogueira, 2012). Other concern is that even after triclosan prohibition in some countries, it stills remains a problem as it aggregates in wastewater sludge and it might be transferred to water environments, persisting for months to years (Lygina et al., 2013). Carbendazim (CBZ) is an active ingredient in systemic fungicides and therefore is largely used in agriculture in several cultures of cereals, sugar, etc. (WHO, 1993). Likewise, carbendazim is still autorized at a national level in some European countries including in the United Kingdom and Portugal (EU Pesticide Database, 2015). Carbendazim has been detected at concentrations of $4.5 \mu \mathrm{g} / \mathrm{L}$ in aquatic systems, whose origin is mainly from agricultural runoffs (Chatupote and Panapitukkul, 2005; Palma et al., 2004). Despite the benefits of their application, these compounds are known to be toxic to several aquatic organisms, including the water flea Daphnia magna (Daam and Brink, 2007; Ferreira et al., 2008; Orvos et al., 2002; Raut and Angus, 2010; Slijkerman et al., 2004). 
Currently, standard ecotoxicology tests mainly focus on the endpoints of mortality and reproduction, providing an effect prediction at the individual and population levels (Hutchinson et al., 2006). In addition, other endpoints closely related to organisms' ecological functions or chemicals' modes of action can also provide crucial information on chemical toxicity and their potential interaction when in mixtures. Feeding inhibition is one of the endpoints that has been used to assess mixture toxicity effects in Daphnia magna (Ferreira et al., 2008; Loureiro et al., 2012; Loureiro et al., 2010), which will provide information on the organisms' function as a filter feeder. Regarding endpoints devoted to chemicals' mode of action, the comet assay is a simple and well-established method that measures the DNA damage in single cells. These DNA strand breaks are sensitive biomarkers of genotoxicity (Collins et al., 1997; Singh et al., 1988). The importance of the comet assay relies on the fact that some effects may not be detected using general endpoints (e. g. growth or reproduction) and at lower concentrations DNA damage may occur and therefore can be measured as an early warning tool (Jha, 2008). Furthermore, Daphnia reproduces asexually, by parthenogenesis, meaning that there is no recombination, making these organisms more vulnerable to DNA damage across generations (Hebert and Ward, 1972; Simon et al., 2003; Sukumaran and Grant, 2013).

Under realistic conditions, organisms are exposed to different and multiple stressors, discharged into the environment from different sources. Usually mixture toxicity prognostic evaluation is based on combining chemicals from similar source of origin. Therefore, mixtures composed of chemicals from different origins that can cooccur in the environment are usually disregarded. To accurately evaluate their effects, modes of action (MoA) should be considered specifically to the study organism. Carbendazim acts on cell division, inhibiting the development of the germ tubes in the 
nucleus and inhibiting the reproduction capacity in D. magna (Canton, 1976). Also carbendazim showed to increase the number of aborted eggs, and an hypothesis was raised on the mitosis inhibition during the eggs division in the brood pouch (Ribeiro et al., 2011). The biocide triclosan inhibits the enoyl-acyl carrier protein reductase (ENR), which is involved in the bacterial lipid biosynthesis, so bacteria are unable to reproduce (Heath and Rock, 2000). In D. magna, triclosan enhances the activity of glutathione Stransferase (GST), and decreases the superoxide dismutase (SOD) activity, which may indicate damage in the cell membranes, confirming that triclosan causes oxidative stress (Peng et al., 2013).

To predict mixture toxicity effects, there are two conceptual models based on non-interaction between chemicals: the Independent Action (IA) and Concentration Addition (CA) models. The IA model assumes that chemicals have different MoA and the CA model assumes that chemicals have the same MoA, being both generally additive models. Considering that the specific MoA of these compounds in daphnids is still vague, but it is assumed to be different, the IA model was used to predict mixture toxicity in in the present study. When additivity is not achieved as the main output result due to interactions that may occur between chemicals, deviations from the two conceptual models (IA and CA) can be observed, such as synergism (more severe effect), antagonism (less severe effect), or dose level dependent deviation (DL: deviations differ at low or high doses of the chemical) and dose ratio dependent deviation (DR: deviations depend on the composition of the mixture). To evaluate these deviations, the MIXTOX is an available tool to be used (developed based on Jonker et al. (2005)). The toxic unit (TU) approach quantifies the relative contribution of each chemical to the toxicity in a mixture and can be calculated as follows:

(Equation 1) $\mathrm{TU}=\mathrm{c} / \mathrm{EC}_{\mathrm{x}}$. 
Here, $\mathrm{c}$ represents the actual concentration of a chemical required to produce a certain effect, $\mathrm{EC}_{\mathrm{x}}$ (effect concentration) (Bliss, 1939; Jonker et al., 2005; Loewe and Muischnek, 1926; Loureiro et al., 2010).

To our knowledge only few studies have investigated the toxic effects of triclosan in D. magna (Flaherty and Dodson, 2005; Orvos et al., 2002) and none addressed the effects of the binary mixture of triclosan and carbendazim. Therefore, and due to their potential co-occurrence from different sources, studies evaluating and predicting their joint effects are helpful to derive more accurate risk assessment results when both compounds are found in the environment.

For all the above mentioned, the aim of the present study was to investigate the effects of triclosan and carbendazim single exposures, and their binary chemical mixture to D. magna. Acute immobilisation and reproduction tests were carried out as standard ecotoxicity tests, the feeding inhibition test was used as a trait-based approach, and the comet assay to unravel genotoxic effects. Interactions between compounds are important to regulatory authorities in Europe (and US), and they are imperative when resulting into synergistic patterns (several cases of synergism are reported in literature in the presence of pesticide mixtures), and therefore this study will highlight additionally the prediction of toxicity patterns that may occur when these two compounds are present in the environment (Cedergreen, 2014).

2. Material and Methods

\subsection{Test organism}


D. magna Straus clone K6 (originally from Antwerp, Belgium) was obtained from continuous culture maintained in a laboratory at the University of Aveiro (Portugal) and cultured in American Society for Testing and Materials (ASTM) moderated-hard-water medium (ASTM, 1980), with a temperature between $19^{\circ} \mathrm{C}$ and $21^{\circ} \mathrm{C}$ and a $16 \mathrm{~h}$ light- $8 \mathrm{~h}$ dark photoperiod. D. magna cultures consisted of $6 \mathrm{~L}$ glass aquariums containing $3 \mathrm{~L}$ of culture medium and 50 daphnids. The medium was renewed three times a week and daphnids were fed with Raphidocelis subcapitata (formerly known as Pseudokirchneriella subcapitata) at a concentration of $3 \times 10^{5}$ cells/mL and supplemented with an organic extract (Marinure seaweed extract, supplied by Glenside Organics Ltd.) (Baird et al., 1989). All tests were performed with D. magna neonates from the third to fifth broods.

\subsection{Test chemicals}

Stock solution for triclosan (Irgasan, CAS No. 3380-34-5, 97\% purity, SigmaAldrich) and carbendazim (CAS No. 10605-21-7, 99.4\% purity, Bayer) were prepared in acetone and then used for preparing the exposure treatments in ASTM medium. Therefore, a solvent control of $100 \mu \mathrm{L}$ acetone/L was also included in all experimental setups as the maximum concentration recommended in the OECD guideline 23 (OECD, 2000).

Chemical analyses were performed to measure concentrations of triclosan and carbendazim in the test medium at Marchwood Scientific Services, Southampton, UK. The analyses for triclosan were performed by Gas Chromatography-Mass Spectrometry (GCMS-MS). A representative portion of the sample $(200-300 \mathrm{~mL})$ was extracted with $20 \mathrm{~mL}$ of acetonitrile (containing $1 \%$ acetic acid). The sample was then subjected to a 
solid phase extraction stage using a $200 \mathrm{mg}$ cartridge. A methanol wash followed and $10 \mu 1$ final injection volume applied. Standards were prepared in solvents at seven levels with recoveries in the range $70-120 \%$. The analyses for carbendazim were performed by Liquid Chromatography-Mass Spectrometry (LSMS-MS) using the Querchers method. A representative portion of the sample (200-300 mL) was extracted with $20 \mathrm{~mL}$ of acetonitrile (containing $1 \%$ acetic acid). This was followed by a partitioning step with magnesium sulphate and a subsequent buffering step with sodium acetate. After mixing an aliquot with methanol, the extract was injected directly into the LCMS-MS system (instrument Agilent 6410 Triple Quad LCMs-MS) without any clean-up. A $10 \mu 1$ injection volume was utilized. Standards were prepared in solvents at seven levels with recoveries in the range $70-120 \%$. The model used assumed that concentrations of the chemical decreased with time, and the change in concentration was given by the following equation:

(Equation 2) $\mathrm{C}_{\mathrm{t}}=\mathrm{C}_{0} \mathrm{e}^{-\mathrm{k} 0 \mathrm{t}}$

Where $\mathrm{C}_{0}$ corresponds to the initial external concentration $(\mu \mathrm{g} / \mathrm{L}), \mathrm{K}_{0}$ corresponds to the constant of degradation of the chemical in the medium (/hour) and $t$ corresponds to time (hours) (Widianarko and Van Straalen, 1996).

\subsection{Single chemical testing}

\subsubsection{Immobilisation test}

Acute tests were performed according to the OECD 202 guideline (OECD, 2004) . Daphnids with less than 24 hours were used to initiate the test. After 24 hours and 48 hours of the beginning of the test, daphnids were observed for immobilisation 
and the number of organisms immobilised was recorded. Organisms that did not move following gentle agitation of the test beakers were considered immobile. The experimental setup consisted in five replicates of five neonates each, for every treatment and controls. Neonates were exposed to test solutions of triclosan and carbendazim (individually) with $50 \mathrm{~mL}$ of ASTM medium with no food during the 48 hours experiment (16:8h light:dark photoperiod and $\left.20 \pm 1^{\circ} \mathrm{C}\right)$. Concentrations used were 400 , $600,800,1000,1200$ and $1400 \mu \mathrm{g} / \mathrm{L}$ for triclosan and 40, 60, 80, 100, 120 and $140 \mu \mathrm{g} / \mathrm{L}$ for carbendazim.

2.3.2 Feeding inhibition test and post exposure tests

Organisms with less than 24 hours old were moved to new culture aquarium and maintained at the same conditions as the main culture until 5-6 days old (corresponding to the fourth instar). The fourth instar was chosen because in this stage the feeding inhibition test (24 hours exposure plus 4 hours post exposure) can be completed within a single moult cycle of the organism, avoiding moulting procedure interference with their feeding activity. This bioassay was based on the methodology described by McWilliam and Baird (2002). Five replicates per treatment and controls with five organisms each were used; each replicate consisted of $170 \mathrm{~mL}$ glass beakers containing ASTM, R. subcapitata at a concentration of $5 \times 10^{5}$ cells $/ \mathrm{mL}$ and the corresponding contaminant in each concentration, corresponding to a final volume of test substance of $100 \mathrm{~mL}$. McWilliam and Baird (2002) performed preliminary laboratory experiments to improve this feeding bioassay with the objective of minimizing variation in baseline feeding rates and the food concentration of $5 \times 10^{5}$ cells $/ \mathrm{mL}$ was sufficient to prevent complete depletion of the food source during the feeding period ( 24 hours). To establish 
that no algae growth was observed during the test, a blank set of $50 \mathrm{~mL}$ beakers with only algae in triplicate was also prepared for each test treatment and controls, in the same conditions as previously described, but without daphnids. The beakers were placed in a temperature controlled room at $20^{\circ} \mathrm{C}$, under darkness, during the 24 hours exposure time (corresponding to the exposure period). Following that, daphnids from each replicate were transferred into $50 \mathrm{~mL}$ beakers with ASTM medium, R. subcapitata $\left(5 \times 10^{5}\right.$ cells $\left./ \mathrm{mL}\right)$ and no toxicant, and were allowed to feed for more 4 hours, also in the dark (corresponding to the post exposure period). In the post exposure period, five blanks with only algae and no daphnids were also prepared and maintained in the same conditions as the other beakers with daphnids, as previously describe for the exposure period. Feeding rates (cells/mL/individual/hour) were determined in accordance with the method described by Allen et al. (1995); algal concentration was measured using a colorimetric method at $440 \mathrm{~nm}$ for both exposure and post exposure periods (Pérez et al., 2011). For triclosan tested concentrations were 100, 300, 500 and $700 \mu \mathrm{g} / \mathrm{L}$ and for carbendazim corresponded to 100, 165, 230, 295, 360 and $425 \mu \mathrm{g} / \mathrm{L}$. Concentrations of the feeding inhibition test were selected based on the immobilisation tests results and on preliminary feeding experiments. In addition, as the aim of the study was to infer on the mixture toxicity approach, a full dose response curve is required for calculating a better prediction of effects and therefore the concentrations used allowed this estimation.

\subsubsection{Reproduction test}

The reproduction test was conducted based on the OECD 211 guideline (OECD, 2008). The physico-chemical parameters $\mathrm{pH}$, electrical conductivity and dissolved oxygen were recorded at the beginning, middle and end of the test. The experimental 
setup included ten replicates per treatment and controls with one neonate each in $50 \mathrm{~mL}$ glass beakers with ASTM hard water, R. subcapitata $\left(3 \times 10^{5}\right.$ cells $\left./ \mathrm{mL}\right)$ and an organic extract (16:8h light:dark photoperiod and $\left.20 \pm 1^{\circ} \mathrm{C}\right)$ with a final volume of test substance of $50 \mathrm{~mL}$. Test solutions were renewed every other day and daphnids were fed daily. During the 21 days period, survival, the number of neonates, time to the first brood and number of broods were monitored. In addition, aborted eggs and abnormal characteristics were registered. Growth of adults (body length, in millimetres, excluding the anal spine) was determined after 21 days of exposure under a stereomicroscope. Six concentrations were tested for both compounds: for triclosan concentrations were 7.5, $15,30,60,120$ and $240 \mu \mathrm{g} / \mathrm{L}$, and for carbendazim corresponded to 5, 20, 35, 50, 65 and $80 \mu \mathrm{g} / \mathrm{L}$. These concentrations allowed a full dose-response pattern required for the mixture toxicity approach.

\subsection{Mixture testing}

From the individual exposure to triclosan and carbendazim $48 \mathrm{~h}-\mathrm{LC}_{50}$ (lethal concentration) and $\mathrm{EC}_{50}$ (effective concentration) values were derived (details in section 2.7) and used to design the mixture experiences. To control differences in daphnids' responses (due to sensitivity variations in organisms), single chemical exposures were performed simultaneously in each mixture test (Loureiro et al., 2010). A full factorial design was used in the immobilisation test (Fig. 1 SD a), by crossing all the concentrations used in the single exposure assessment. In the feeding inhibition and reproduction tests, a fixed ratio design was conducted to avoid mortality at higher chemical combinations (Fig. $1 \mathrm{SD} b$ and $\mathrm{c}$ ). In the feeding inhibition and reproduction tests, $\mathrm{EC}_{50}$ values obtained from single exposures were used to calculate toxic units 
(Fig. 1 SD), and the toxic unit sum ( $\sum \mathrm{TUs}$ ) never exceeded 2 to prevent mortality. For the feeding inhibition and reproduction experiments, concentrations were based on expected toxic strengths of $0.375(0.125+0.25 ; 0.25+0.125), 0.5(0.125+0.375$; $0.25+0.25 ; 0.375+0.125), 0.75(0.125+0.625 ; 0.25+0.5 ; 0.375+0.375 ; 0.5+0.25 ;$ $0.625+0.125), 1(0.125+0.875 ; 0.25+0.75 ; 0.375+0.625 ; 0.5+0.5 ; 0.625+0.375$; $0.75+0.25 ; 0.875+0.125), 1.5(0.75+0.75 ; 1+0.50 ; 0.50+1), 1.75(1+0.75 ; 0.75+1)$ and 2 $(1+1)$ toxic units $\left(\mathrm{TU}_{\text {Chemical } 1}+\mathrm{TU}_{\text {Chemical 2 }}\right)$.

2.4.1 Immobilisation, feeding inhibition and reproduction tests

Bioassays described above were also carried out with small adaptations mainly by decreasing the number of replicates used, to increase the number of mixture treatments, increasing therefore covering the most of the response surface. This has been argued to increase both reliability and power of the analysis, as the response surface analysis is based on a regression model (Loureiro et al., 2010).

In the immobilisation test three replicates of five neonates each were used; each replicate had a final volume of $50 \mathrm{~mL}$ of the test substance. Chemical single exposure were carried out simultaneously with concentrations of 400, 600, 800, 1000 and 1200 $\mu \mathrm{g} / \mathrm{L}$ for triclosan and of $20,70,120,170$ and $220 \mu \mathrm{g} / \mathrm{L}$ for carbendazim and the combinations of both, by using a full factorial design with a total of 25 treatments.

The experimental design for the feeding inhibition test included, simultaneously, a single evaluation of each compound and a set of binary mixtures (23 combinations). In this mixture experiment we used one replicate for each treatment and each replicate contained five daphnids (5-6 days old, corresponding to the fourth instar); in the 24 hours exposure period each replicate had a final volume of $100 \mathrm{~mL}$ of the test substance 
and in the 4 hours post exposure period each replicate had $50 \mathrm{~mL}$ of the test substance (McWilliam and Baird, 2002). In single experiments, concentrations were 200, 350, 500 and $650 \mu \mathrm{g} / \mathrm{L}$ and 150, 225, 300 and $375 \mu \mathrm{g} / \mathrm{L}$ for triclosan and carbendazim, respectively. In combined experiments (after the TU calculation), concentrations ranged from 60 to $500 \mu \mathrm{g} / \mathrm{L}$ and 30 to $260 \mu \mathrm{g} / \mathrm{L}$ for triclosan and carbendazim, respectively (Fig. $1 \mathrm{SD}$ b).

In reproduction experiments, survival, number of neonates produced per organism, time to the first brood and number of broods were monitored during 21 days; each control and concentration were conducted with one replicate with one daphnid each; each replicate had a final volume of $50 \mathrm{~mL}$ of the test substance In single chemical experiments, concentrations applied in the reproduction test were $17.5,35,70$, 140 and $280 \mu \mathrm{g} / \mathrm{L}$ for triclosan and for carbendazim were 4, 8, 16, 32 and $64 \mu \mathrm{g} / \mathrm{L}$; in combined experiments, after the TU calculation, concentrations ranged from 25.75 to $206 \mu \mathrm{g} / \mathrm{L}$ for triclosan and from 2.89 to $23.12 \mu \mathrm{g} / \mathrm{L}$ for carbendazim (Fig. 1 SD c).

2.5 Comet assay: single and mixture testing

D. magna juveniles were exposed to concentrations of 5, 20 and $25 \mu \mathrm{g} / \mathrm{L}$ of carbendazim, corresponding to the NOEC (no observed effect concentration), LOEC (lowest-observed-effect concentration) and $\mathrm{EC}_{50}$ values for carbendazim in the reproduction test. For triclosan exposure, daphnids were exposed to 120, 160 and 206 $\mu \mathrm{g} / \mathrm{L}$ of triclosan, where the extremes concentrations correspond to the NOEC and $\mathrm{EC}_{50}$ of triclosan in the reproduction tests, however the middle concentration of triclosan was chosen considering the reproduction results. Mixture exposures of $120 \mu \mathrm{g} / \mathrm{L}$ of triclosan plus $5 \mu \mathrm{g} / \mathrm{L}$ of carbendazim, $160 \mu \mathrm{g} / \mathrm{L}$ of triclosan plus $20 \mu \mathrm{g} / \mathrm{L}$ of carbendazim, and 
$206 \mu \mathrm{g} / \mathrm{L}$ of triclosan plus $25 \mu \mathrm{g} / \mathrm{L}$ of carbendazim, were also tested in D. magna juveniles with less than 24 hours. Mixture exposures were conducted at the same time as individual ones. These concentrations were chosen considering the results from the previous tests performed. Under these concentrations daphnids were not expected to die and concentrations where: no effects were observed, low effect levels were observed or where a significant impairment was observed in terms of reproduction (the most sensitive parameter used in the present study) were included in this set up. This was mainly based on the knowledge that some effects may not be detected using individual endpoints (e. g. feeding activity or reproduction), however, at lower concentrations a sub cellular effect, like DNA damage, may occur (Jha, 2008). In addition, the concentration range used enable to derive $\mathrm{EC}_{50}$ values needed for the mixture analyses using the MIXTOX tool. At all experiments, four replicates with fifteen juveniles of Daphnia $(<24 h)$ each, were used for each control and concentrations. Each replicate consisted of one glass beaker containing $150 \mathrm{~mL}$ ASTM (plus contaminants in treatment situation). After 24 hours exposure, organisms were collected and pooled for the comet assay as described by Nogueira et al. (2006). Positive controls were performed by using daphnid cells previously exposed to hydrogen peroxide $\left(\mathrm{H}_{2} \mathrm{O}_{2}\right)$. To prevent UV induced DNA damage, assays were conducted under yellow light. Organisms were placed in 1.5 mL Eppendorfs containing $1 \mathrm{~mL}$ of phosphate-buffered saline (PBS) with 10\% dimethyl sulfoxide (DMSO) and $20 \mu \mathrm{M}$ ethylene diamine tetra-acetic acid (EDTA). Organisms were gently disintegrated mechanically with an appropriate spatula (carapaces were removed when possible). Eppendorfs were centrifuged (200 g) during 10 minutes at $4^{\circ} \mathrm{C}$. The supernatant was gently removed. From this suspension of cells, $10 \mu \mathrm{L}$ were transferred to Eppendorfs containing $0.5 \%$ of low melting point agarose, at $37^{\circ} \mathrm{C}$. The mixture was spread on the microscope glass slides, and then the cover slips were 
applied. Slides were placed on ice for 10 minutes. Subsequently, slides (without coverslips) were placed, for at least 1 hour, in a solution of $10 \mathrm{mM}$ Tris-HCl, $100 \mathrm{mM}$ EDTA, $2.5 \mathrm{NaCl}, 10 \%$ DMSO, 10\% Triton X-100, pH 10, for cell lysis. Slides were left for 15 minutes in the electrophoresis tank filled with a $10 \mathrm{M} \mathrm{NaOH}, \mathrm{Na}_{2}$ EDTA solution (to allow DNA denaturation and unwinding) before electrophoresis took place. For the electrophoresis, an electric current of $300 \mathrm{~mA}$ (30 Volts) was applied for 10 minutes. To neutralize, slides were washed with Tris-HCl. Slides were dehydrated with absolute ethanol $100 \%$ for 10 seconds (left to dry for 1 day in the dark). Slides were stained with $100 \mu \mathrm{L}$ ethidium bromide $(20 \mu \mathrm{L} / \mathrm{mL})$, before analysis in a fluorescent microscope (Olympus BX41TF, China) at 400x magnification. The slide reading was done randomly, to avoid bias on the results and one hundred cells per slide were examined. DNA damage was visually scored: cells were scored on a 0 to 4 scale, as described by Duthie and Collins (1997). Fig. 2 SD represents a comet type scale in daphnid cells. Type 0 represents no DNA damage, type 1 and 2 represent mild to moderate damage, respectively, and type 3 and 4 represent extensive DNA damage. Therefore, the total score for 100 cells could range between 0 (all comets with no damage) to 400 (all comets with maximal damage). A percentage of DNA damage (for the single experiments) and percentage of no DNA damage (for the MIXTOX analysis) was calculated.

2.6 Statistical Analysis

2.6.1. Single chemical testing

Differences between organisms exposed to the negative control and to the solvent control were checked using a t-test (Systat Software Inc., 2008). 
Data from the immobilisation tests of D. magna were analysed using a probit analysis and a $48 \mathrm{~h}-\mathrm{LC}_{50}$ value was derived (Minitab).

The statistical analysis for the sub-lethal parameters (feeding activity, reproduction and DNA damage) was performed with SigmaPlot v11.0 software (Systat Software Inc., 2008). To detect significant differences between treated groups and control values a one-way analysis of variance (ANOVA) was used. The normality of the data was tested using the Kolmogorov-Smirnov test. A Dunnett's test was carried out when differences were obtained in data that followed a normal distribution. If data were not normally distributed and data transformation did not correct for normality, a Kruskal-Wallis test was also used and the multiple comparisons Dunn's Method. The $50 \%$ effective concentration $\left(\mathrm{EC}_{50}\right)$ values were calculated using a nonlinear regression with a logistic/sigmoid function using always the one with better adjustment (Systat Software Inc., 2008).

\subsubsection{Mixture testing}

The toxic effects of the mixtures were analysed by comparing the obtained effects with the expected mixture effects (based on single exposures) using the reference conceptual model, IA, in the MIXTOX tool described by Jonker et al. (2005). The mathematical formulation of the IA model is based on probability of responses and is expressed as:

$$
\text { (Equation 3) } \mathrm{Y}=\mu \max \prod_{\mathrm{i}=1}^{\mathrm{n}} \mathrm{qi}(\mathrm{Ci})
$$

Where $\mathrm{Y}$ denotes the biological response, $\mathrm{C}_{\mathrm{i}}$ is the concentration of chemical $\mathrm{i}$ in the mixture, qi $(\mathrm{Ci})$ the probability of non-response, $\mu_{\max }$ the control response for endpoints and $\prod$ the multiplication function. 
Deviations from this model were modelled for synergism or antagonism, dose ratio and dose level dependencies by adding two extra parameters: a and b; its biological interpretation is described in Table $1 \mathrm{SD}$ and further explanation can be found in Jonker et al. (2005). The method of maximum likelihood was used to fit the data and the fundamental procedure to minimize the Sum of Squared Residuals (SS) was used by running the Solver Function in Microsoft ${ }^{\circledR}$ Excel.

3. Results

\subsection{Chemical analysis}

Chemical analysis showed that the carbendazim concentration decreased over time, with a decay rate $\left(\mathrm{K}_{0}\right)$ of $0.03 /$ hour (st. error= 0.005$)$, and only $18 \%$ of the initial concentration remained after $48 \mathrm{~h}$. Regarding triclosan, the obtained decay rate $\left(\mathrm{K}_{0}\right)$ was $0.06 /$ hour (st. error $=0.010$ ), and after $48 \mathrm{~h}$ of the initial concentration only $1.3 \%$ of triclosan concentration remained.

\subsection{Single chemical testing}

The validation of the immobilisation tests, as established by the OECD 202 guideline, was fulfilled (OECD, 2004). Also, the reproduction tests was valid as established by the OECD 211 guideline, with the parent animals in the control showing less than $20 \%$ of mortality and the mean number of live offspring per Daphnia at the end of the test was higher than 60. Regarding physico-chemical properties: $\mathrm{pH}$, 
dissolved oxygen concentrations and conductivity (Table 2 SD), all parameters were also in accordance with the OECD 211 guideline (OECD, 2008).

In all bioassays, there were no differences between the negative and the solvent controls at the $5 \%$ level. Therefore all comparisons between chemical treatments and the control group were carried out with the solvent control.

The $\mathrm{EC}_{50}$ values obtained for each single chemical exposure for triclosan and carbendazim are summarized in Table 1. Values from the single chemical bioassays were used to calculate the TU values for the experimental setup of the mixture exposure but also to compare accuracy of results from the single exposures used (simultaneously) in the mixture approach.

Acute exposures to triclosan and carbendazim derived $48 \mathrm{~h}-\mathrm{LC}_{50}$ values of 856.8 $\mu \mathrm{g} / \mathrm{L}$ (st. error=28.4) and $87.6 \mu \mathrm{g} / \mathrm{L}$ (st. error=5.6), respectively.

The feeding activity upon exposure to triclosan and carbendazim followed a dose-response relationship (Fig. 1). The $\mathrm{EC}_{50}$ value calculated for triclosan was of 549.3 $\mu \mathrm{g} / \mathrm{L}$ (st. error=19.2, $\mathrm{r}^{2}=0.88$ ), still followed by a similar effect regarding the $4 \mathrm{~h}$ post exposure, where an $\mathrm{EC}_{50}$ of $478.0 \mu \mathrm{g} / \mathrm{L}$ (st. error $=33.5, \mathrm{r}^{2}=0.75$ ) was derived. For carbendazim, $\mathrm{EC}_{50}$ values derived were of $325.6 \mu \mathrm{g} / \mathrm{L}$ (st. error=90.4, $\mathrm{r}^{2}=0.71$ ) and $176.5 \mu \mathrm{g} / \mathrm{L}$ (st. error=9.9, $\mathrm{r}^{2}=0.93$ ) for the $24 \mathrm{~h}$ exposure and $4 \mathrm{~h}$ post exposure, respectively.

In the reproduction test, $100 \%$ mortality was observed after 16 days of exposure in the two highest concentrations of carbendazim (65 and $80 \mu \mathrm{g} / \mathrm{L}$; data not shown) and therefore these two concentrations were excluded from the reproduction output analysis. The mean number of neonates produced per daphnia decreased significantly with increasing concentrations of carbendazim (ANOVA, $F_{4,32}=61.72 p<0.001$ ) (Fig. 2 b). However, for triclosan, only the highest concentration $(240 \mu \mathrm{g} / \mathrm{L})$ induced a significant 
decrease of the number of neonates when compared to the control (ANOVA, $\left.\mathrm{F}_{6,59}=101.6 \mathrm{p}<0.001\right)$ (Fig. 2 a). For carbendazim the (mean) number of aborted eggs increased with carbendazim concentrations, as shown in Fig. 2 b. The calculated $\mathrm{EC}_{50}$ values for the effects on reproduction for daphnids exposed to carbendazim were 23.2 $\mu \mathrm{g} / \mathrm{L}$ (st. error=2.2, $\mathrm{r}^{2}=0.88$ ) for the number of neonates per female and $28.8 \mu \mathrm{g} / \mathrm{L}$ (st. error $=7.4, \mathrm{r}^{2}=0.62$ ) for the number of aborted eggs, with a NOEC and a lowestobserved-effect concentration (LOEC) of $5 \mu \mathrm{g} / \mathrm{L}$ and $20 \mu \mathrm{g} / \mathrm{L}$, respectively, for the number of neonates (Table 1).

The body length of adult daphnids after the 21 days of exposure to triclosan was similar within all concentrations when compared to the control. For carbendazim, the concentration of $35 \mu \mathrm{g} / \mathrm{L}$ was the only one where daphnids length decreased significantly when compared to the control (Kruskal-Wallis one-way ANOVA, $\mathrm{H}=14.91, \mathrm{DF}=4 ; \mathrm{p}=0.005$; Dunn's Method $\mathrm{p}<0.05$ ) (Fig. 3). The calculated $\mathrm{EC}_{50}$ value for the reproduction (number of neonates per female) of daphnids exposed to triclosan was $203.2 \mu \mathrm{g} / \mathrm{L}$ (st. error=10.7, $\mathrm{r}^{2}=0.89$ ), with a NOEC and LOEC of $120 \mu \mathrm{g} / \mathrm{L}$ and 240 $\mu \mathrm{g} / \mathrm{L}$, respectively (Table 1).

\subsection{Mixture testing}

The combined toxicity of triclosan and carbendazim in the immobilisation test was significantly adjusted to the IA model (Table 2). Continuing the nested framework for assessing potential deviations, the dose level deviation pattern showed to present the best fit (Table 2). Regarding the isobolograms (Fig. 4 a1), and also the derived positive parameter a means that there was an antagonism at low doses of both chemicals and synergism at high doses; and parameter $\mathrm{b}$ was lower than one, meaning that the change from antagonism to synergism would occur at higher concentrations than the tested 
ones. Therefore synergism was not observed in the isobologram and the main pattern for this endpoint was antagonism (see Table 1 SD).

In the feeding inhibition of D. magna (24h exposure), the IA model fitted our data significantly with no further improvement by adding parameters for deviations, showing a pattern for additivity on effects (Table 2, Fig. 4 b1). In the $4 \mathrm{~h}$ post exposure period of this test, the same additivity was observed (Table 2, Fig. 4b'1).

For the reproduction data (total number of neonates per female) the MIXTOX results showed that the conceptual model (IA) adjusted well and significantly to this data (Table 2, Fig. 4c1), with no significant deviations.

\subsection{Comet assay: single and mixture testing}

Both compounds and the mixture showed an increase in DNA damage with increasing concentrations, comparing with the control situation (Fig. 5). For both chemicals the percentage of damage was significant at all the concentrations tested (Dunnett's Method $\mathrm{p}<0.05$ ). The lowest concentration used in the comet assay corresponds to the NOECs from the reproduction tests, where no effects on the reproduction output were observed. However, these carbendazim and triclosan levels/concentrations already induced a significant increase in DNA damage.

Regarding mixture toxicity effects, in order to get a more accurate analysis of the dataset, the percentage (\%) of DNA damage was converted into $\%$ of cell viability (\% of no damage) in D. magna, in order to get a dose-response curve with decrease on results, when concentrations were increased. From the MIXTOX model fit (Table 2, Fig. 6) it was observed that the data was well modelled by the DR deviation (Table 2). In the DR deviation, when testing two compounds in a mixture, deviations will depend on the mixture composition, and the predominance of the chemical which is inducing 
effects, i.e, synergism is induced mainly by one of the chemicals in the binary mixture, and the other chemical is responsible for the opposite pattern, antagonism (Jonker et al., 2005; Loureiro et al., 2010). In our study, for the \% of no DNA damage, the biological interpretation of the derived extended parameters $\mathrm{a}$ and $\mathrm{b}$ showed that synergism was mainly driven by triclosan and carbendazim was the main responsible for the increase of cell viability (\% of no damage) (antagonism) (see Table $1 \mathrm{SD})$. The selection of this deviation is supported by the $r^{2}$ value and mostly by the SS, which are the lowest comparing with all the others deviations in the IA model.

\section{Discussion}

\subsection{Single chemical testing}

In the immobilisation tests, and from the $48 \mathrm{~h}-\mathrm{LC}_{50}$ values derived, carbendazim presented to be approximately ten times more toxic than triclosan. Previous studies have reported $48 \mathrm{~h}-\mathrm{LC}_{50}$ value of $390 \mu \mathrm{g} / \mathrm{L}$ for triclosan (Orvos et al., 2002) and 110, 157 and $350 \mu \mathrm{g} / \mathrm{L}$ for carbendazim (Ferreira et al., 2008; U.S.EPA, 2000) showing a high variability in the results depending on the study.

In the single exposure to carbendazim, an $\mathrm{EC}_{50}$ value of $325.6 \mu \mathrm{g} / \mathrm{L}$ was derived for the feeding inhibition (24h exposure) endpoint. Feeding activity of D. magna exposed to this compound was already investigated in the work of Ribeiro et al. (2011) and Ferreira et al. (2008), where $\mathrm{EC}_{50}$ values for the 24 hours exposure were lower: $179.87 \mu \mathrm{g} / \mathrm{L}$ and $97.54 \mu \mathrm{g} / \mathrm{L}$, respectively. Regarding triclosan, and to our knowledge, the effects of triclosan on the feeding activity of $\mathrm{D}$. magna have not been reported in literature. In the post exposure period, when daphnids were moved to clean medium (with no contaminant), there was an increase on feeding rates (comparing with $24 \mathrm{~h}$ 
exposure) in the two first concentrations for both triclosan and carbendazim (Fig. 1). This pattern was also observed by Ferreira et al. (2008), which suggests that this increase on feeding rates upon exposure could indicate compensation induced by a previous chemical stress. However, daphnids from the highest concentrations of both compounds may not have recovered from the chemical exposure, having still a decrease on feeding rates in the post exposure period (Fig. 1). McWilliam and Baird (2002) verified that some compounds also produced feeding depression during this period. Therefore, in risk assessment, adding this kind of information on post exposure effects can be considered ecologically relevant, as it highlights the ability of organisms to recover after short periods of exposure (McWilliam and Baird, 2002).

In the reproduction test with carbendazim, there was an increase in the number of aborted eggs with increasing concentrations (Fig 2b). This pattern was also observed by Ribeiro et al. (2011) and it is probably related to the described mode of action of carbendazim in fungi, which inhibits the mitosis, and its teratogenic effects have been reported along the years (Davidse, 1977). In the study of Ribeiro et al. (2011), after 21 days exposure an $\mathrm{EC}_{50}$ value of $40.05 \mu \mathrm{g} / \mathrm{L}$ was determined for D. magna, which is in the same order of magnitude from the one in the present study $\left(\mathrm{EC}_{50}=23.2 \mu \mathrm{g} / \mathrm{L}\right)$, although two times higher. In the 70's, fungicides belonging to the same group of carbendazim: benzimidazoles showed effects on the reproductive capacity of D. magna, with an $\mathrm{EC}_{50}$ value of ca. $20 \mu \mathrm{g} / \mathrm{L}$ of BCM (methyl benzimidazole-2-yl carbamate) (Canton, 1976). Since the 90's toxicity of carbendazim has been studied, and van Wijngaarden et al (1998) studied the effect of Derosal (a formulation containing carbendazim) in some aquatic invertebrates, including Daphnia magna; this organism was relatively sensitive with a NOEC value (for the number of neonates per female) of $25.8 \mu \mathrm{g} / \mathrm{L}$. For the endpoint reproduction of D. magna as well, Van den Brink et al. 
(2000) reported a 28 days $\mathrm{NOEC}$ and $\mathrm{EC}_{50}$ value of 33 and $37 \mu \mathrm{g} / \mathrm{L}$, respectively. Other effects that might be related to effects on reproduction in these crustaceans are the production of male daphnids. This phenomena was observed upon an exposure of 40 $\mu \mathrm{g} / \mathrm{L}$ of carbendazim to the crustacean Moina micrura which lead to the production of males with abnormal antennules (Miracle et al., 2011) .

For triclosan the calculated $\mathrm{EC}_{50}$ value (regarding the number of neonates per female) was $203.2 \mu \mathrm{g} / \mathrm{L}$. Some studies tested the effects of triclosan on the reproduction of Daphnia (Flaherty and Dodson, 2005; Orvos et al., 2002), however, to our knowledge no $\mathrm{EC}_{50}$ value was derived. Tatarazako et al. (2004) tested the effect of triclosan on the reproduction of the crustacean Ceriodaphnia dubia, and an $\mathrm{IC}_{50}$ (inhibiting concentration with a reduction of $50 \%$ in reproduction) similar to our study was obtained $(220 \mu \mathrm{g} / \mathrm{L})$.

In the single exposure to carbendazim, daphnids feeding inhibition occurred at higher concentrations than those impairing reproduction. These could be related to the age of the organisms, as in the reproduction test, daphnids had less than $24 \mathrm{~h}$ when exposure started, and 5 to 6 days when they were exposed to the chemical in the feeding inhibition tests, possibly being less sensitive. In addition, the exposure in the feeding inhibition test lasted for $24 \mathrm{~h}$ and in the reproduction test the exposure was longer $(21$ days).

Other organisms have been used to test the toxic effects of both compounds and different degrees of sensitivity were found. For the algae Tetrahymena pyriformis, carbendazim have showed to be far less toxic with an $\mathrm{EC}_{50}$ value of $6380 \mu \mathrm{g} / \mathrm{L}$, however carbendazim was more toxic to the fish Ictalurus punctatus with an $\mathrm{EC}_{50}$ value of $10 \mu \mathrm{g} / \mathrm{L}$ (RIVM, 2008). For triclosan, an $\mathrm{LC}_{50}$ value of $1700 \mu \mathrm{g} / \mathrm{L}$ was found with a 
96 hours exposure using the fish Oryzias latipes and for the algae Anabaena flos aquae triclosan was highly toxic with an $\mathrm{EC}_{50}$ value of $1.6 \mu \mathrm{g} / \mathrm{L}$ (Dann and Hontela, 2011).

The genotoxicity of triclosan and carbendazim was evaluated in daphnid cells, where we witnessed that both compounds caused an increase in DNA damage with increasing concentrations (comparing with the control) (Fig. 5). This was observed even at NOEC levels derived for the reproduction tests, showing that the DNA damage can be considered in this study as an early warning endpoint, regarding effects. Over the last years, genotoxic effects were reported for both compounds in different organisms. JanakiDevi and colleagues (2013) determined that in the marine invertebrate Donax faba, different concentrations of carbendazim induced higher DNA damage comparing with the control samples. In the zebra mussel, Dreissena polymorpha, and in the algae, Closterium ehrenbergii, triclosan induced DNA damage as well (Binelli et al., 2009; Ciniglia et al., 2005). The DNA strand breaks caused by genotoxic compounds may give rise to chromosomal aberrations that can promote cell death and may be related with mitotic anomalies, and consequently lead to acquisition of DNA damage (Ganem and Pellman, 2012; Jha, 2008). This is probably related with the presence of aborted eggs upon carbendazim exposure both in the present study and in another study described by Ribeiro et al. (2011), considering that the mode of action of carbendazim on fungi is related with mitosis. DNA damage occurred at exposures of $5 \mu \mathrm{g} / \mathrm{L}$ of carbendazim and there are reported environmental concentrations in surface waters of 4.5 $\mu \mathrm{g} / \mathrm{L}$ of carbendazim (in the basin of the Traiguén River, Chile) (Palma et al., 2004). Therefore, this study highlights the importance of lower organizational level parameters to understand mechanisms but also to be used as early warning tools (no effects 
occurred at the individual level in this specific concentration, while DNA damage was already occurring).

There are not many Maximum Allowable Concentration (MAC) available in legislation regarding triclosan. The Russian Federation established a MAC for carbendazim in surface waters of $0.1 \mathrm{mg} / \mathrm{L}$ (WHO, 1993). Considering the results of our study, where carbendazim concentrations below $0.1 \mathrm{mg} / \mathrm{L}(100 \mu \mathrm{g} / \mathrm{L})$ caused effects at the reproduction and at sub cellular level (DNA damage), this might represent a low protection level, and therefore risk. An identical hazard situation might occur for triclosan, as high triclosan concentrations, $6000-14000 \mu \mathrm{g} / \mathrm{L}$, were detected in a USA river receiving a treated wastewater discharge from a manufacturing plant. Moreover in Spain primary effluents of an urban WWTP presented a concentration of $269 \mu \mathrm{g} / \mathrm{L}$ of triclosan (Jungclaus et al., 1978; NICNAS, 2009).

\subsection{Mixture testing}

Considering the possible effects of the mixture of triclosan and carbendazim in aquatic systems and the unawareness of the specific molecular mode of action of triclosan and carbendazim on D. magna as stressed before, the IA model was tested and deviations from additivity occurred in some of the case studies (Table 2). An additive effect (IA model) was observed for the feeding inhibition and on the reproduction data. Other studies on the effects of insecticides binary mixtures to D. magna have demonstrated that both mixture conceptual models (CA and IA) can explain data equally well, however, they suggested that the CA was the most conservative model to predict mixture effects (Syberg et al., 2008) and potentially the easiest to use for legislators. For the case of triclosan, DeLorenzo and Fleming (2008) tested the mixture 
of triclosan with the pharmaceutical fluoxetine (marketed as Prozac®) on the 96h growth test with the algae Dunaliella tertiolecta and an additive effect was also observed.

In this study an additive effect was observed in the feeding inhibition test ( $24 \mathrm{~h}$ exposure). Ferreira et al. (2008) tested the effect of the binary mixture of carbendazim and cadmium and the combination of carbendazim and the environmental variable dissolved oxygen, on the feeding activity (24h exposure) of D. magna, and they found an antagonistic pattern for both combinations. In the immobilisation test antagonism was observed at low doses of the chemical mixture of triclosan and carbendazim (in the DL deviation). Opposite effects were reported for carbendazim and copper mixture in the reproduction of Caenorhabditis elegans, where synergism was observed at low doses and antagonism at high doses of those chemicals (Jonker et al., 2004).

Despite this additive effect, when looking at the DNA damage in daphnid cells, synergism (in the DR deviation) was also observed and it was mostly related to triclosan. Synergism is considered the worst scenario because it means that the toxic effects of the mixture are more severe than expected regarding the individual chemical toxicity, and there is an augmentation of toxicity (Jonker et al., 2005; Santos et al., 2011a). Since triclosan interferes with the fatty acid biosynthesis in bacteria, the majority of the studies that are available in the literature are performed in microorganisms. In Vibrio fischeri a synergistic effect was observed in the presence of triclosan jointly with LAS (linear alkylbenzene sulfonates), which is another compound found in domestic wastewaters (Farré et al., 2008). In other bacteria, such as Staphylococcus aureus, Staphylococcus epidermidis and Escherichia coli, synergism was found in the antibiofilm activity when these bacteria were exposed to triclosan and DispersinB $®$ (Darouiche et al., 2009). The same pattern (synergism) was observed in 
the Salmonella Typhimurium biofilms, when exposed to triclosan and the antibiotic ciprofloxacin (Tabak et al., 2009). Therefore, this result for synergism may be indicative of the actual underestimation of the risk to aquatic communities exposed to these two compounds and seems somehow related to the presence of triclosan. In the present study DNA damage provided an output considerably important as it showed effects at NOEC levels using standardised tests (reproduction), but also in the mixture approach. When looking at the currently used risk evaluations those are mainly focused on individual toxicity of compounds and disregard their potential interaction inside organisms. The comet assay results provided also an input showing DNA damage higher than expected if one regards the toxicity of both compounds acting singly. Interactions between compounds can influence several processes in organisms, including bioavailability, uptake, metabolization, excretion, etc. One possible explanation for the synergy in the simultaneous presence of carbendazim and triclosan could be probably related with changes in the metabolic enzyme activities. One similar example was observed with the lipophilic insecticide (pyrethroid) that enhanced the toxicity when mixed with the azole fungicide (prochloraz). Here the azole inhibited the metabolization of the pesticides in daphnids, increasing the overall toxicity (Cedergreen, 2014).

From the results of the present study, we derived different patterns of toxicity for this chemical mixture for different endpoints, including additivity, synergism and antagonism, showing that chemicals can also interact among them in the organisms (Loureiro et al., 2010). As shown in our work, even within the same organism (D. magna) different evaluated endpoints provided different outputs regarding mixture toxicity. This was already observed in other studies, where effects on the same organism varied depending on the endpoint chosen (Loureiro et al., 2010; Santos et al., 2011b; 
Turgut and Formin, 2002). This is possibly related to the chosen endpoint, which is interconnected with the chemical mode of action, but also with the potential mechanism of interaction between chemicals inside organisms.

\section{Conclusions}

Daphnia magna showed to be more sensitive to carbendazim than to triclosan. Through the comet assay it was observed that both compounds caused DNA damage in daphnids cells even at NOEC levels for reproduction, with carbendazim showing higher toxicity. In the mixture toxicity all possible outcomes were observed: non-interaction or additivity, synergistic and antagonistic patterns. The reference model, IA, explained the results from feeding inhibition and reproduction data, and on the other hand dose level or dose ratio dependencies were observed for the other endpoints (immobilisation and DNA damage). As a worst case scenario, synergism was attained using DNA damage as endpoint, mainly induced by triclosan.

Usually risk assessment is carried out by focusing on the toxicity of single chemicals, however, and as we know, in the environment compounds appear as complex mixtures. Considering these, mixture toxicity studies will provide more and useful information to predict risk more accurately.

\section{Acknowledgments}

This work was supported by the project RePulse- Responses of Daphnia magna exposed to chemical pulses and mixtures throughout generations (FCOMP-01-0124-FEDER-019321; Ref ${ }^{\mathrm{a}}$. FCT PTDC/AAC-AMB/117178/2010), by funding FEDER through COMPETE- Programa Operacional Factores de Competitividade, and by National funding through FCT-Fundação para 
a Ciência e Tecnologia. Ana Rita Rego Gouveia Silva was funded by the project "MARPRO-

Conservation of marine protected species in Mainland Portugal" through the doctoral fellowship

(BD/UI88/5534/2011) and Andreia Cruz was funded by an individual post-doctoral grant

(BPD/UI88/2886/2013), within the project "Sustainable Use of Marine Resources" - MARES

(CENTRO-07-ST24-FEDER-002033), financed by QREN, Mais Centro- Programa Operacional

Regional do Centro e União Europeia/ Fundo Europeu de Desenvolvimento Regional.

References

Allen, Y., Calow, P., Baird, D. J., 1995. A mechanistic model of contaminant-induced feeding inhibitionin Daphnia magna. Environmental Toxicology and Chemistry. 14, 1625-1630.

ASTM, 1980. Standard practice for conducting acute toxicity tests with fishes, macroinvertebrates and amphibians. Report E-729-80. American Standards for Testing and Materials.

Baird, D. J., Barber, I., Bradley, M., Calow, P., Soares, A. M. V. M., 1989. The Daphnia bioassay: a critique. Hydrobiologia. 188/189, 403-406.

Bester, K., 2003. Triclosan in a sewage treatment process - balances and monitoring data. Water Research. 37, 3891-3896.

Binelli, A., Cogni, D., Parolini, M., Riva, C., Provini, A., 2009. Cytotoxic and genotoxic effects of in vitro exposure to Triclosan and Trimethoprim on zebra mussel (Dreissena polymorpha) hemocytes. Comparative Biochemistry and Physiology Part C: Toxicology \& Pharmacology. 150, 50-56.

Bliss, C., 1939. The toxicity of poisons applied jointly. Annals of Applied Biology. 26, 585-615.

Canton, J., 1976. The toxicity of benomyl, thiophanate-methyl, and BCM to four freshwater organisms. Bulletin of Environmental Contamination and Toxicology. 16, 214-218.

Cedergreen, N., 2014. Quantifying Synergy: A Systematic Review of Mixture Toxicity Studies within Environmental Toxicology. Plos One. 9, e96580.

Chatupote, W., Panapitukkul, N., 2005. Regional Assessment of Nutrient and Pesticide Leaching in the Vegetable Production Area of Rattaphum Catchment, Thailand. Water, Air, \& Soil Pollution: Focus. 5, 165-173.

Ciniglia, C., Cascone, C., Giudice, R. L., Pinto, G., Pollio, A., 2005. Application of methods for assessing the geno- and cytotoxicity of Triclosan to $\mathrm{C}$. ehrenbergii. Journal of Hazardous Materials. 122, 227-232.

Collins, A. R., Dobson, V. L., Dusinska M., Kennedy, G., R., S., 1997. The comet assay: what can it really tell us? . Mutation Research. 375, 183-93.

Council Directive, 1999 edition. Council Directive 76/768/EEC on the Approximation of the Laws of the Member States Relating to Cosmetic Products.

Daam, M. A., Brink, P. J., 2007. Effects of Chlorpyrifos, Carbendazim, and Linuron on the Ecology of a Small Indoor Aquatic Microcosm. Archives of Environmental Contamination and Toxicology. 53, 22-35.

Dann, A. B., Hontela, A., 2011. Triclosan: environmental exposure, toxicity and mechanisms of action. J Appl Toxicol. 31, 285-311. 
Darouiche, R. O., Mansouri, M. D., Gawande, P. V., Madhyastha, S., 2009. Antimicrobial and antibiofilm efficacy of triclosan and Dispersin $B^{\circledR}$ combination. Journal of Antimicrobial Chemotherapy. 64, 88-93.

Davidse, L. C., 1977. Mode of action, selectivity and mutagenicity of benzimidazole compounds. European Journal of Plant Pathology. 83, 135-144.

DeLorenzo, M. E., Fleming, J., 2008. Individual and Mixture Effects of Selected Pharmaceuticals and Personal Care Products on the Marine Phytoplankton Species Dunaliella tertiolecta. Archives of Environmental Contamination and Toxicology. 54, 203-210.

Duthie, S. J., Collins, A. R., 1997. The influence of cell growth, detoxifying enzymes and DNA repair on hydrogen per oxide-mediated DNA damage (measured using the comet assay) in human cells. Free Radical Biology \& Medicine. 22, 717-24.

EU Pesticide Database, 2015. EU Pesticide Database, European Comission. http://ec.europa.eu/sanco_pesticides/public/?event=activesubstance.detail\&language $=E N \&$ selectedID $=1080$.

Farré, M., Asperger, D., Kantiani, L., González, S., Petrovic, M., Barceló, D., 2008. Assessment of the acute toxicity of triclosan and methyl triclosan in wastewater based on the bioluminescence inhibition of Vibrio fischeri. Analytical and Bioanalytical Chemistry. 390, 1999-2007.

Ferreira, A. L. G., Loureiro, S., Soares, A. M. V. M., 2008. Toxicity prediction of binary combinations of cadmium, carbendazim and low dissolved oxygen on Daphnia magna. Aquatic Toxicology. 89, 28-39.

Flaherty, C. M., Dodson, S. I., 2005. Effects of pharmaceuticals on Daphnia survival, growth, and reproduction. Chemosphere. 61, 200-207.

Gaffar, A., Afflitto, J., Nabi, N., Kruger, I., Olsen, S., 1994. Recent advances in plaque, gingivitis, tartar and caries prevention technology. International Dental Journal. 44, 63-70.

Ganem, N. J., Pellman, D., 2012. Linking abnormal mitosis to the acquisition of DNA damage. The Journal of Cell Biology. 199, 871-881.

Heath, R. J., Rock, C. O., 2000. A Triclosan-resistant bacterial enzyme. . Nature. 406, 145.

Hebert, P. D. N., Ward, R. D., 1972. Inheritance during parthenogenesis in Daphnia magna. Genetics. 71, 639-642.

Hutchinson, T., Shillabeer, N., Winter, M., Pickford, D., 2006. Acute and chronic effects of carrier solvents in aquatic organisms: A critical review. Aquatic Toxicology. 76, 69-92.

JanakiDevi, V., Nagarani, N., YokeshBabu, M., Kumaraguru, A. K., Ramakritinan, C. M., 2013. A study of proteotoxicity and genotoxicity induced by the pesticide and fungicide on marine invertebrate (Donax faba). Chemosphere. 90, 1158-1166.

Jha, A. N., 2008. Ecotoxicological applications and significance of the comet assay. Mutagenesis. 23, 207-221.

Jones, R. D., Jampani, H. B., Newman, J. L., Lee, A. S., 2000. Triclosan: a review of effectiveness and safety in health care setting. American Journal of Infection Control. 28, 184-196.

Jonker, M. J., Piskiewicz, A. M., Castellà, N. I. I., Kammenga, J. E., 2004. Toxicity of binary mixtures of cadmium-copper and carb copper to the nematode Caenorhabditis elegans. Environmental Toxicology and Chemistry. 23, 1529-1537.

Jonker, M. J., Svendsen, C., Bedaux, J. J. M., Bongers, M., Kammenga, J. E., 2005. Significance testing of synergistic/antagonistic, dose level-dependent, or dose ratio-dependent effects in mixture dose-response analysis. environmental Toxicology and Chemistry. 24, 2701-2713.

Jungclaus, G. A., Lopez-Avila, V., Hites, R. A., 1978. Organic compounds in an industrial wastewater: a case study of their environmental impact. Environmental Science and Technology. 12, 88-97.

Lishman, L., Smyth, S. A., Sarafin, K., Kleywegt, S., Toito, J., Peart, T., Lee, B., Servos, M., Beland, M., Seto, P., 2006. Occurrence and reductions of pharmaceuticals and personal 
care products and estrogens by municipal wastewater treatment plants in Ontario, Canada. Science of the Total Environment. 367, 544-558.

Loewe, S., Muischnek, H., 1926. Combinated effects I announcement - implements to the problem. Naunyn-Schmiedebergs Arch .Exp. Pathol. Pharmakol. 114, 313-326.

Loureiro, S., Meyer, T. L., Ferreira, A. L. G., Amorim, M. J. B., Soares, A. M. V. M., 2012. Single and joint effects of perchlorates to Daphnia magna: additivity and interaction patterns. Fresenius Environmental Bulletin. 21, 844-852.

Loureiro, S., Svendsen, C., Ferreira, A. L. G., Pinheiro, C., Ribeiro, F., Soares, A. M. V. M., 2010. Toxicity of three binary mixtures to Daphnia magna: Comparing chemical modes of action and deviations from conceptual models. Environmental Toxicology and Chemistry. 29, 1716-1726.

Lygina , O., Lyubchik, A., Neng , N., Sharipova, A., Issakhov, M., Nogueira, J., Fonseca, I., Aidarova, S., Bekturganova, N., Lyubchik, S., 2013. Review of current situation with triclosan's harmful disinfection by-products pathways into environment. Scientific Israel- Technological Advantages. 15, 49-64.

McWilliam, R. A., Baird, D. J., 2002. Postexposure feeding depression: a new toxicity endpoint for use in laboratory studies with Daphnia magna. Environmental Toxicology. 21, 11981205.

Minitab, 2003. Minitab Incorporation Statistical Software, Version 13.0. State College, PA, USA.

Miracle, M. R., Nandini, S., Sarma, S. S. S., Vicente, E., 2011. Endocrine disrupting effects, at different temperatures, on Moina micrura (Cladocera: Crustacea) induced by carbendazim, a fungicide. Hydrobiologia. 668, 155-170.

Neng, N. R., Nogueira, J. M., 2012. Development of a bar adsorptive micro-extraction-largevolume injection-gas chromatography-mass spectrometric method for pharmaceuticals and personal care products in environmental water matrices. Anal Bioanal Chem. 402, 1355-64.

NICNAS, 2009. National Industrial Chemicals Notification and Assessment Scheme (NICNAS). Australian Government, Department of Health and Ageing. Priority Existing Chemical Assessment Report No. 30, Triclosan.

Nogueira, P. R., Lourenço, J., Mendo, S., Rotchell, J. M., 2006. Mutation analysis of ras gene in the liver of European eel (Anguilla anguilla L.) exposed to benzo[a]pyrene. Marine Pollution Bulletin. 52, 1611-1616.

OECD, 2000. OECD Series on testing and assessment, Number 23. Guidance document on aquatic toxicity testing of difficult substances and mixtures.

OECD, 2004. OECD guidelines for testing of chemicals. Guideline 202: Daphnia sp., Acute immobilisation test, adopted April 2004.

OECD, 2008. OECD guidelines for testing of chemicals. Guideline 211: Daphnia magna Reproduction test, adopted October 2008.

Orvos, D. R., Versteeg, D. J., Inauen, J., Capdevielle, M., Rothenstein, A., Cunningham, V., 2002. Aquatic toxicity of triclosan. Environmental Toxicology and Chemistry. 21, 1338-1349.

Palma, G., Sánchez, A., Olave, Y., Encina, F., Palma, R., Barra, R., 2004. Pesticide levels in surface waters in an agricultural-forestry basin in Southern Chile. Chemosphere. 57, 763-770.

Pavlaki, M. D., Pereira, R., Loureiro, S., Soares, A. M. V. M., 2011. Effects of binary mixtures on the life traits of Daphnia magna. Ecotoxicology and Environmental Safety. 74, 99-110.

Peng, Y., Luo, Y., Nie, X.-P., Liao, W., Yang, Y.-F., Ying, G.-G., 2013. Toxic effects of Triclosan on the detoxification system and breeding of Daphnia magna. Ecotoxicology. 22, 13841394.

Pérez, J., Domingues, I., Soares, A. M. V. M., Loureiro, S., 2011. Growth rate of Pseudokirchneriella subcapitata exposed to herbicides found in surface waters in the Alqueva reservoir (Portugal): a bottom-up approach using binary mixtures.

Ecotoxicology. 20, 1167-1175. 
Raut, S. A., Angus, R. A., 2010. Triclosan has endocrine-disrupting effects in male western mosquitofish,Gambusia affinis. Environmental Toxicology and Chemistry. 29, 12871291.

Reiss, R., Mackay, N., Habig, C., Griffin, J., 2002. An Ecological Risk Assessment For Triclosan In Lotic Systems Following Discharge From Wastewater Treatment Plants In The United States. Environmental Toxicology and Chemistry. 21, 2483-2492.

Ribeiro, F., Ferreira, N. C. G., Ferreira, A., Soares, A. M. V. M., Loureiro, S., 2011. Is ultraviolet radiation a synergistic stressor in combined exposures? The case study of Daphnia magna exposure to UV and carbendazim. Aquatic Toxicology. 102, 114-122.

RIVM, 2008. Environment risk limits for carbendazim 601716014/2008 National Institute for Public Health and the Environment. Bilthoven, the Netherlands. .

Santos, M. J. G., Morgado, R., Ferreira, N. G. C., Soares, A. M. V. M., Loureiro, S., 2011a. Evaluation of the joint effect of glyphosate and dimethoate using a small-scale terrestrial ecosystem. Ecotoxicology and Environmental Safety. 74, 1994-2001.

Santos, M. J. G., Soares, A. M. V. M., Loureiro, S., 2011b. Joint toxicity of three plant protection products to Triticum aestivum (L.) and Brassica rapa (L.). Journal of Soils and Sediments. 11, 990-999.

Simon, J. C., Delmonte, F., Rispe, C., Crease, T., 2003. Phylogenetic relationships between parthenogens and their sexual relatives: the possible routes to parthenogenesis in animals. Biological Journal of the Linnean Society. 79, 151-163.

Singer, H., Müller, t., Tixier, C., Pillonel, L., 2002. Triclosan: Occurrence and Fate of a Widely Used Biocide in the Aquatic Environment: Field Measurements in Wastewater Treatment Plants, Surface Waters, and Lake Sediments. Environ. Sci. Technol. 36, 4998-5004.

Singh, N. P., McCoy, M. T., Tice, R. T., Schneider, E. L., 1988. A simple technique for quantitation of low levels of DNA damage in individual cells. Experimental Cell Research. 175, 184-191.

Slijkerman, D. M. E., Baird, D. J., Conrad, A., Jak, R. G., van Straalen, N. M., 2004. Assessing structural and functional plankton responses to carbendazim toxicity. Environmental Toxicology and Chemistry. 23, 455-462.

Sukumaran, S., Grant, A., 2013. Multigenerational demographic responses of sexual and asexual Artemia to chronic genotoxicity by a reference mutagen. Aquatic Toxicology. 144-145, 66-74.

Syberg, K., Elleby, A., Pedersen, H., Cedergreen, N., Forbes, V. E., 2008. Mixture toxicity of three toxicants with similar and dissimilar modes of action to Daphnia magna. Ecotoxicology and Environmental Safety. 69, 428-436.

Systat Software Inc., 2008. SigmaPlot for Windows (version 11.0). San Jose, California, USA.

Tabak, M., Scher, K., Chikindas, M. L., Yaron, S., 2009. The synergistic activity of triclosan and ciprofloxacin on biofilms of Salmonella Typhimurium. Fems Microbiology Letters. 301, 69-76.

Tatarazako, N., Ishibashi, H., Teshima, K., Kishi, K., Arizono, K., 2004. Effects of triclosan on various aquatic organisms. Environmental Sciences. 11, 133-140.

Turgut, C., Formin, A., 2002. Sensitivity of the rooted macrophyte Myryophyllum aquaticum (Vell.) Verdcourt to seventeen pesticides determined on the basis of EC50. Bulletin of Environmental Contamination and Toxicology. 69, 601-608.

U.S.EPA, 2000. United States Environmental Protection Agency. Pesticide ecotoxicity database (Environmental Effects Database (EEDB)). Office of Pesticide Programs. Environmental Fate and Effects Division, US EPA, Washington, DC.

Van den Brink, P. J., Hattink, J., Bransen, F., Van Donk, E., Brock, T. C., 2000. Impact of the fungicide carbendazim in freshwater microcosms. II. Zooplankton, primary producers and final conclusions. Aquatic Toxicology. 48, 251-264. 
van Wijngaarden, R. P. A., Crum, S. J. H., Decraene, K., Hattink, J., van Kammen, A., 1998.

Toxicicity of derosal (active ingredient carbendazim) to aquatic invertebrates.

Chemosphere. 37, 673-683.

WHO, 1993. Carbendazim (Environmental Health Criteria 149). International Programme on Chemical Safety, Geneva.

[http://www.inchem.org/documents/hsg/hsg/hsg82_e.htm\#SectionNumber:1.4].

Widianarko, B., Van Straalen, N. M., 1996. Toxicokinetics-based survival analysis in bioassays using nonpersistent chemicals. Environmental Toxicology and Chemistry. 15, 402-406.

a)

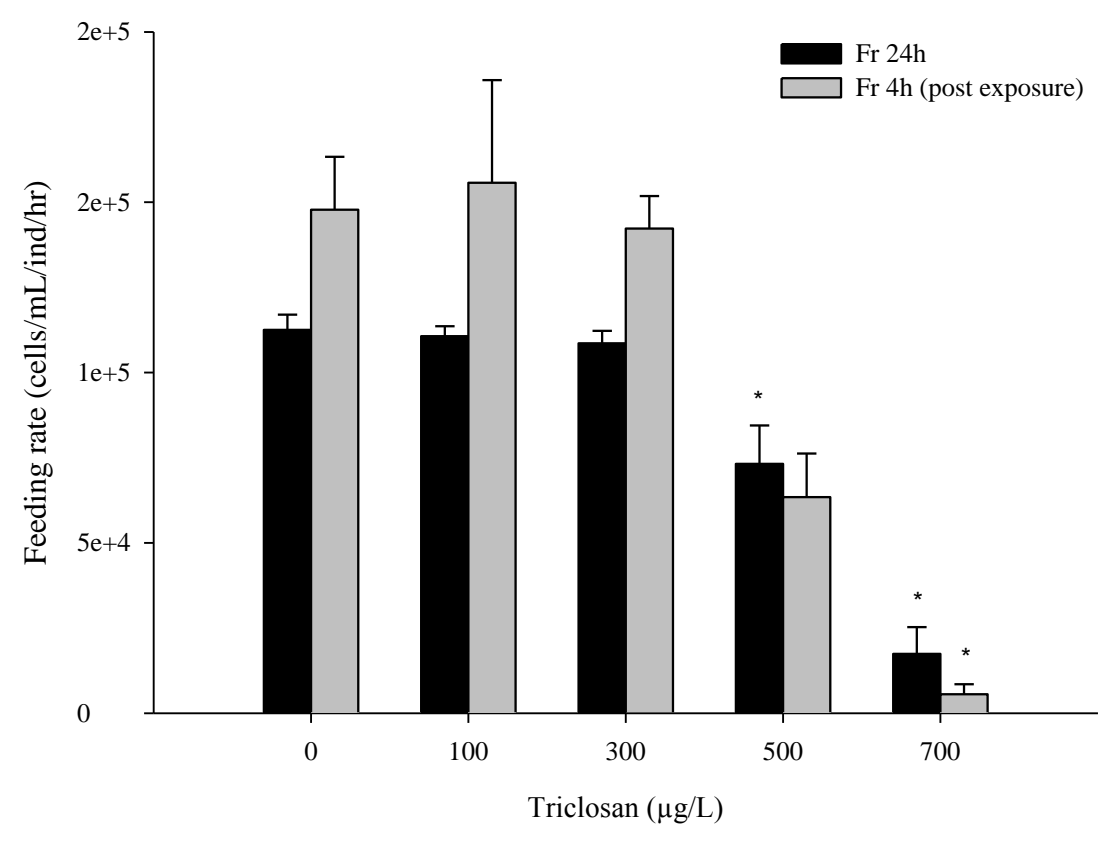

b) 


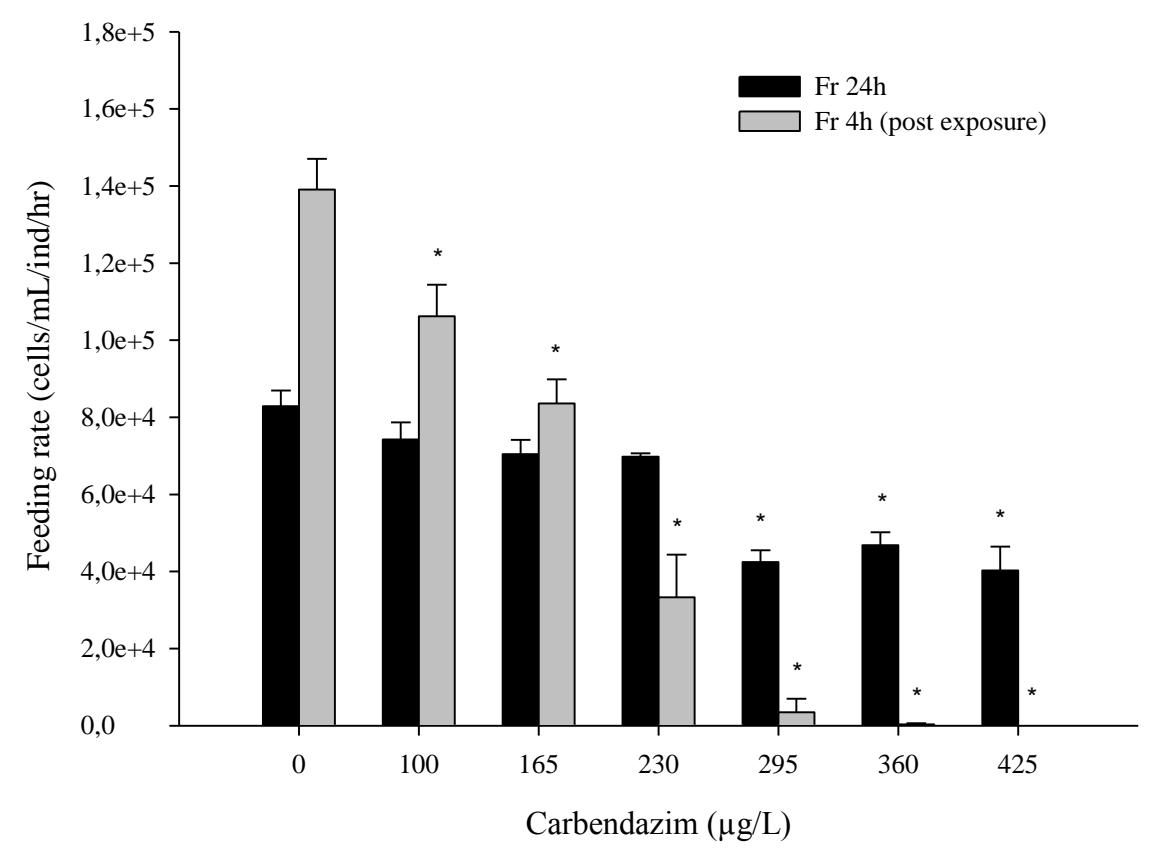

Figure 1. Feeding rate (cells $/ \mathrm{mL}$ per daphnia per hour) of Daphnia magna ( $\mathrm{n}=5,5$ replicates) exposed to a) triclosan and b) carbendazim. Data is expressed as mean values and standard error. Dark bars represent the feeding rate $(\mathrm{Fr})$ after a $24 \mathrm{~h}$ exposure period and grey bars represent the feeding rate $(\mathrm{Fr})$ during the 4h post exposure. $(* \mathrm{p}<0.05$, Dunnett's Method, in comparison with the control).

a)

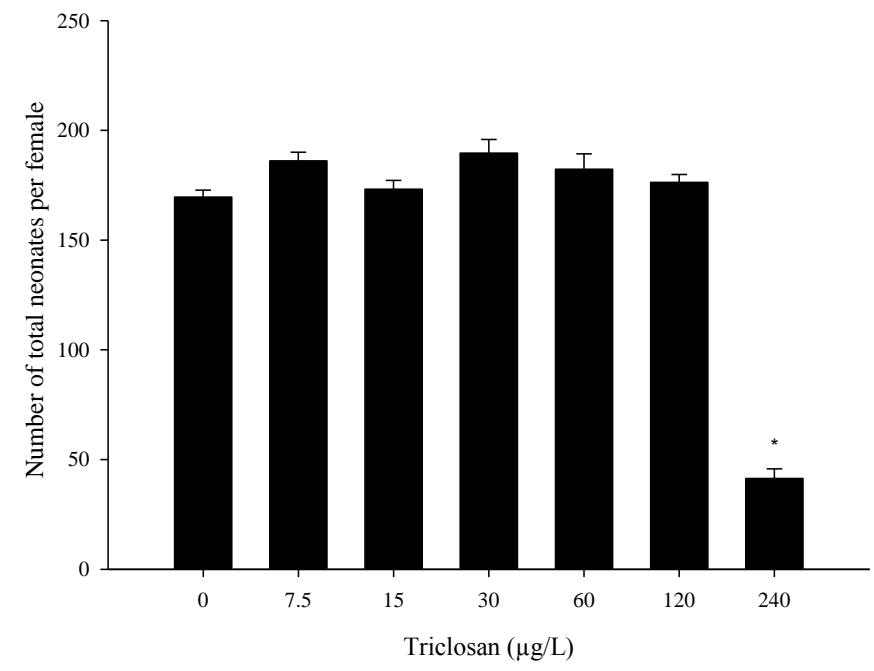

b) 


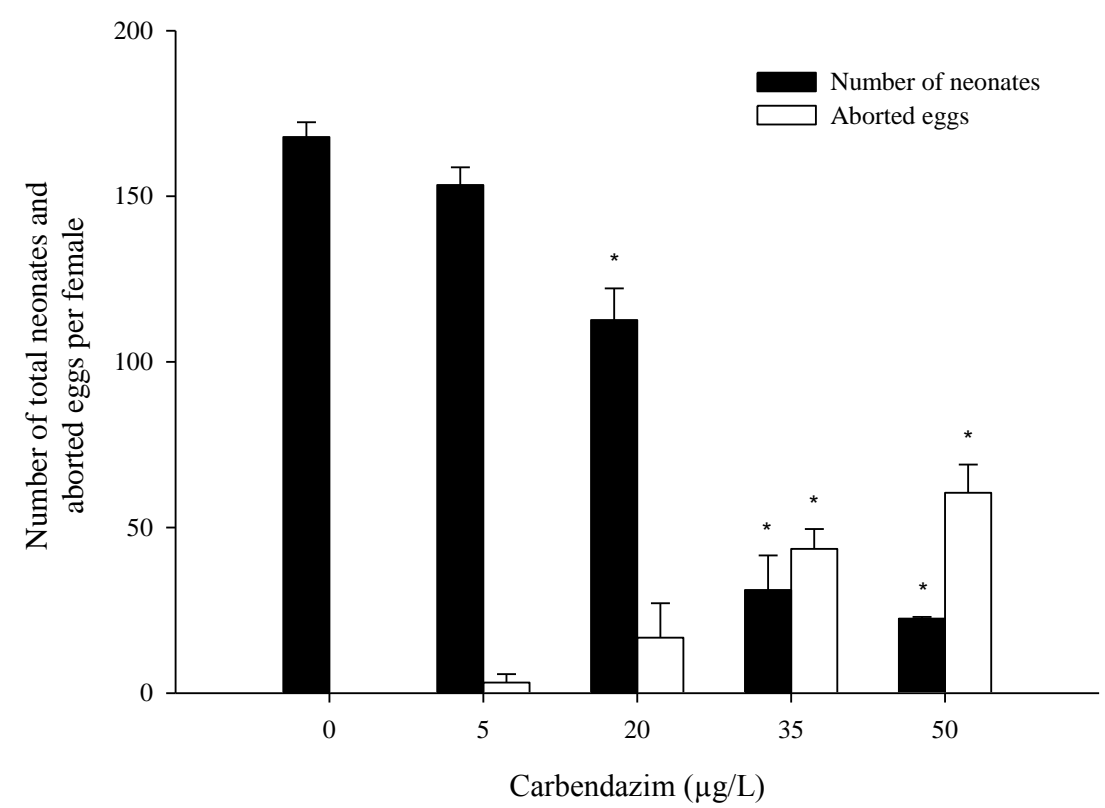

Figure 2. Reproduction effort during a 21 days exposure period of D. magna ( $n=1,10$ replicates) to a) triclosan and b) carbendazim. Black bars refer to the number of neonates and white bars to the number of aborted eggs. Data is expressed as mean values and standard error ( ${ }^{*} \mathrm{p}<0.05$, Dunnett's and Dunn's (only for aborted eggs data) Method, in comparison with the control).

a)

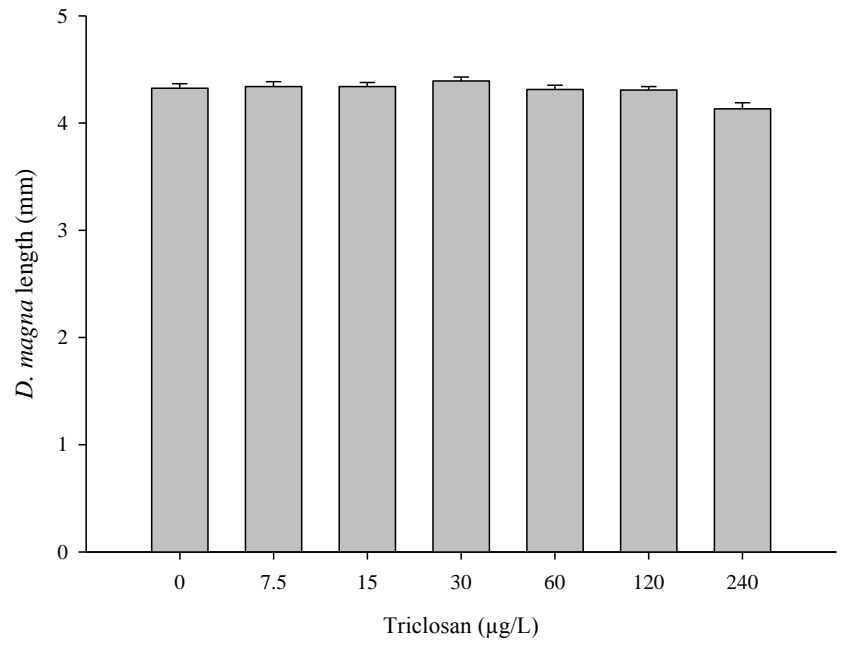

b) 


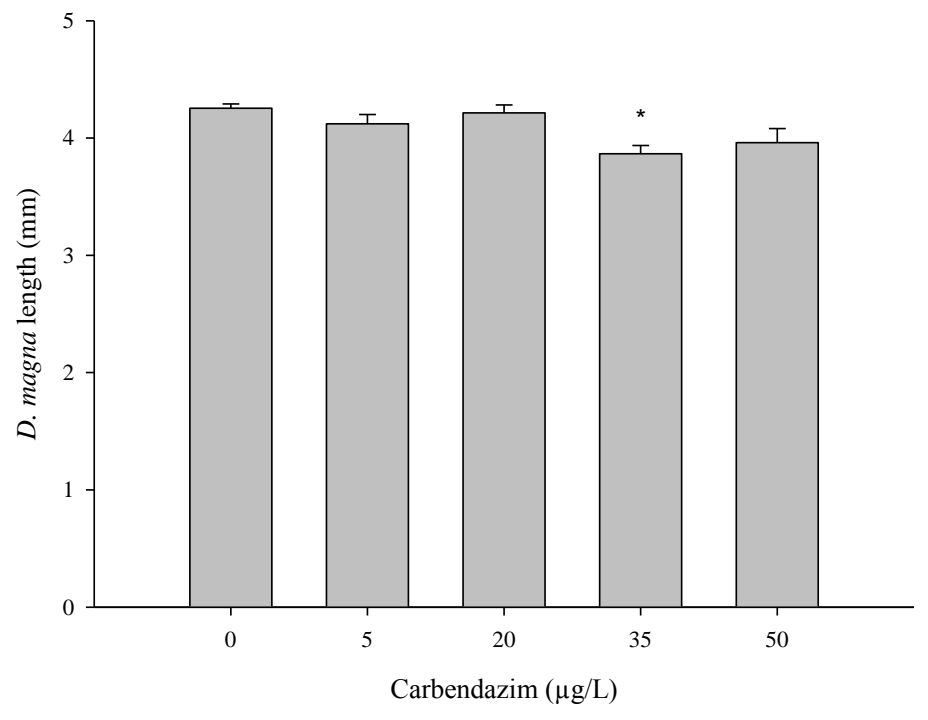

Figure 3. Body length (mm) of D. magna ( $\mathrm{n}=1,10$ replicates) after 21 days exposure to a) triclosan and $b$ ) carbendazim. Data is expressed as mean values and standard error (* $\mathrm{p}<0.05$, Dunnett's and Dunn's Method, for triclosan and carbendazim, respectively, in comparison with the control).
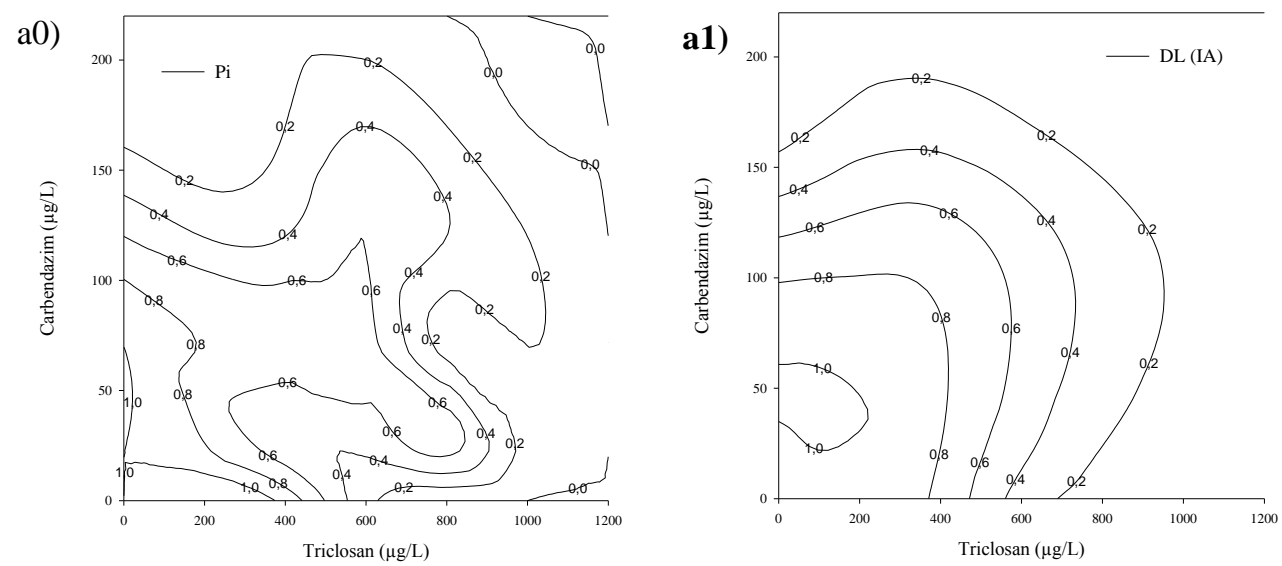

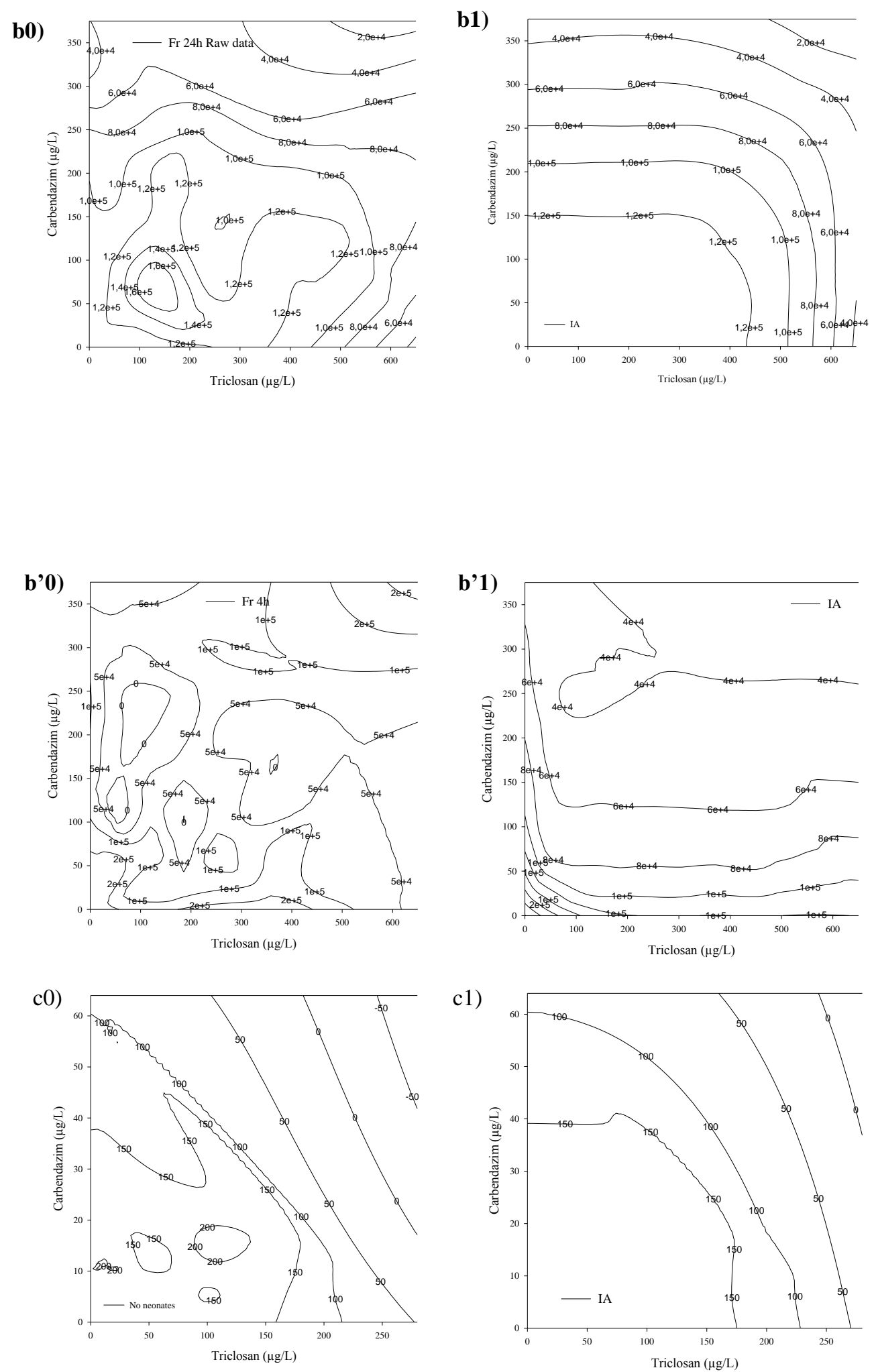
Figure 4. Concentration-response relationship for the binary mixture of triclosan and carbendazim (2D isobolic surfaces). a) Survival of Daphnia magna ( $\mathrm{Pi})(\mathrm{n}=5,3$ replicates): a0) observed data a1) showing a DL deviation from the IA model b) Feeding rate of D. magna (cells $/ \mathrm{mL} / \mathrm{ind} / \mathrm{hr})$ at $24 \mathrm{~h}(\mathrm{n}=5,1$ replicate): b0) observed data b1) showing no deviation to the IA model b') Feeding rate of D. magna (cells/mL/ind/hr) at 4 h post exposure ( $n=5,1$ replicate): b’0) observed data; b'1) showing no deviation to the IA model c) Reproduction of D. magna (number of total neonates per female after 21 days of exposure) ( $\mathrm{n}=1,1$ replicate): $\mathrm{c} 0$ ) observed data; $\mathrm{c} 1$ ) showing no deviation to the IA model.

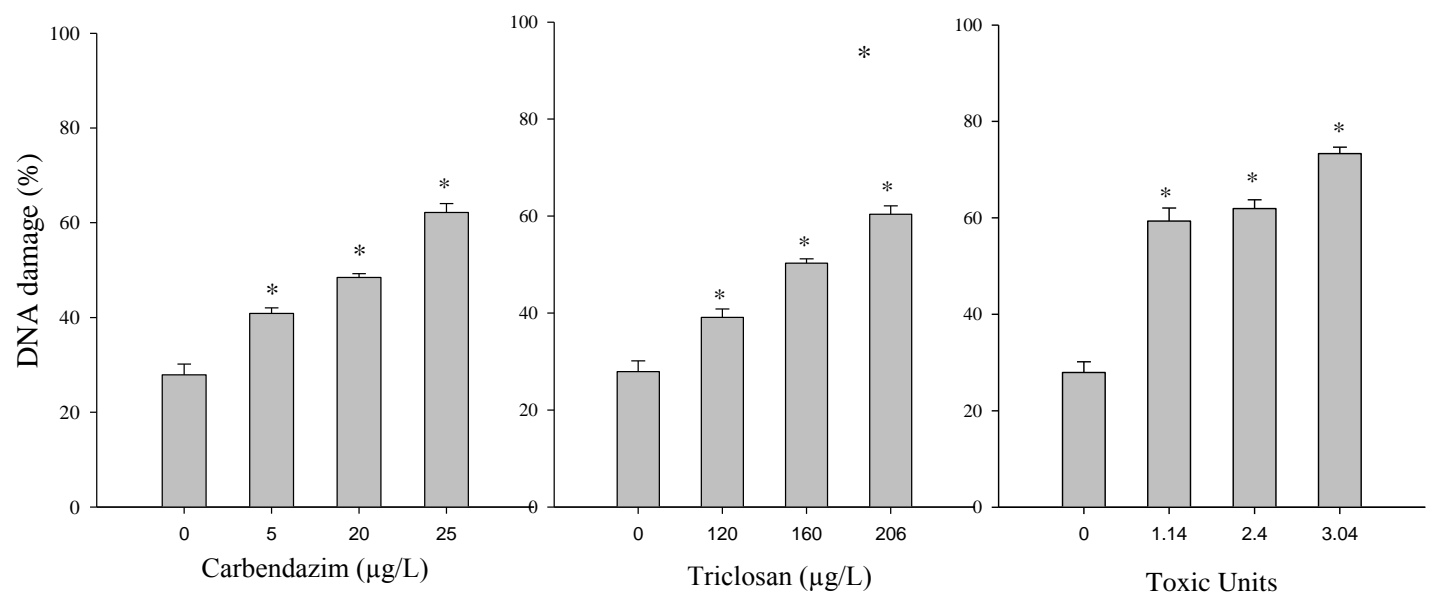

Figure 5. DNA damage (\%) in D. magna cells exposed to carbendazim, triclosan and mixture of both (Toxic Units) ( $\mathrm{n}=15,4$ replicates) $(* \mathrm{p}<0.05$, Dunnett's Method, in comparison with the control). 
$\mathrm{a} 0)$

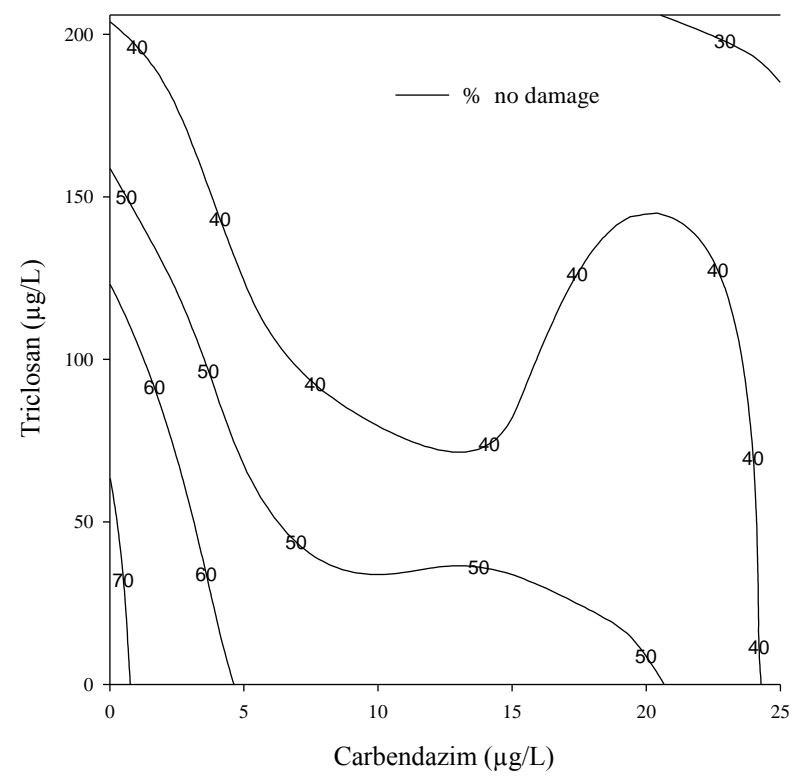

a1)

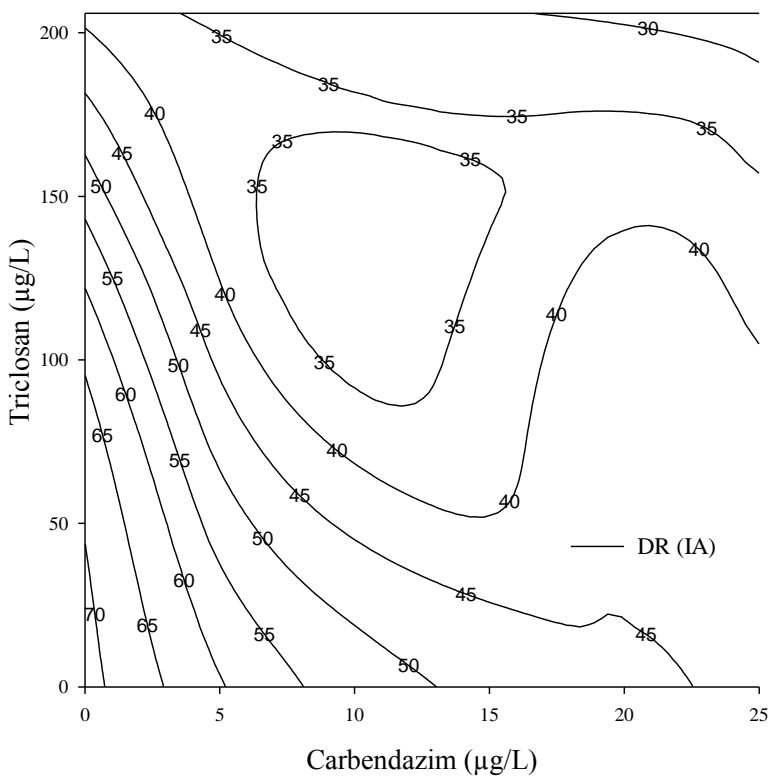

Figure 6. Concentration-response relationship for the binary mixture of triclosan and carbendazim (2D isobolic surfaces) ( $\mathrm{n}=15,4$ replicates) a) \% of no DNA damage on D. magna cells a0) observed data a1) showing a DR deviation from the IA model.

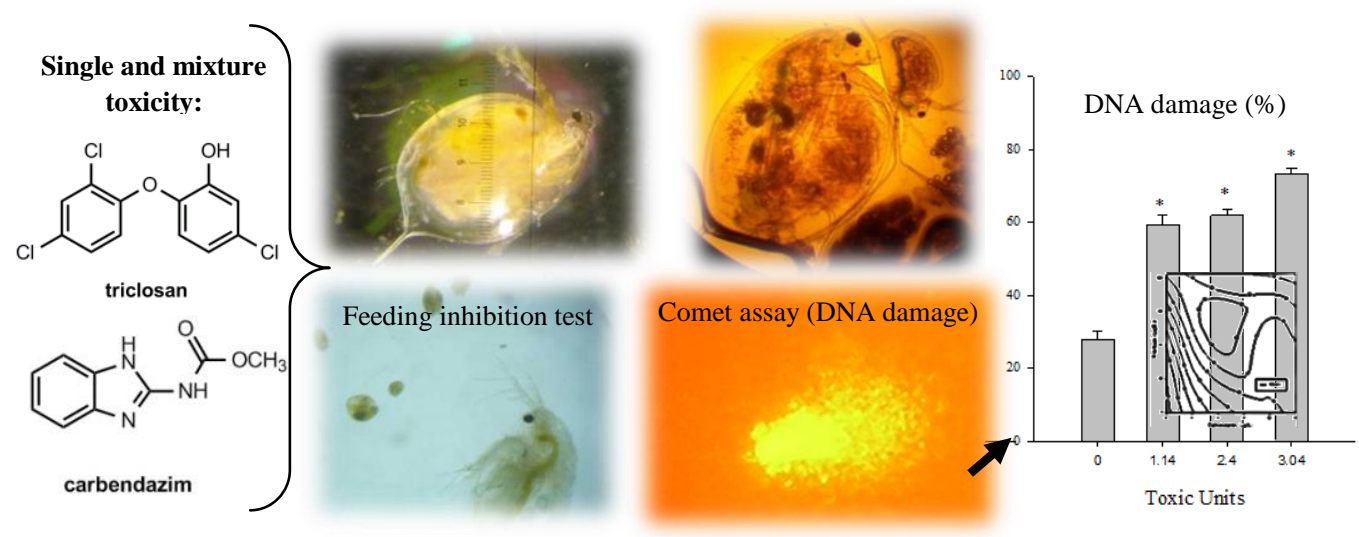

